\title{
Impact of pulmonary hypertension on early hemodynamics, morbidity and mortality after orthotopic heart transplantation. A single center study
}

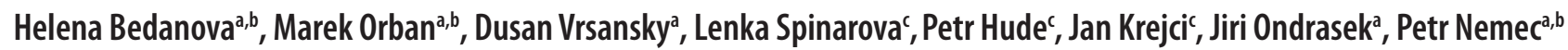

Aims. To determine the effect of pre-existing pulmonary hypertension (PHT) on early hemodynamics, morbidity and mortality after heart transplantation ( $\mathrm{HTX})$.

Methods. Data were prospectively collected from 149 patients, who underwent HTx between January 2000 and December 2007. The subjects were divided into 3 groups: Group A ( $n=84)$ without PTH, group B ( $n=50)$ with mild to moderate PTH and group $C(n=15)$ with severe PTH. We studied hemodynamic profile, tricuspid valve regurgitation (TR), incidence of acute cellular rejections (AR), infections, duration of hospitalization, 30-day mortality and a longterm survival.

Results. Baseline characteristics were similar in all groups. Using vasodilator treatment PVR was successfully brought down to normal range $2.5 \pm 0.6$ Wood' units (WU) on the day 1 following the surgery in all groups. Over $80 \%$ of patients were treated in Group C, 32\% in Group A and 46\% in Group B. There was no significant difference in the severity of TR among the 3 groups early after HTx (severe TR was observed in $46 \%, 54 \%, 33 \%$, respectively). There was no significant difference in incidence of AR ( $\mathrm{G} \geq 2$ Banff classification) $(23 \%, 23 \%, 33 \%$, respectively), infections ( $28 \%, 32 \%, 33 \%$, respectively) or duration of hospitalization (30,30, 28 days, respectively). There was no correlation between pre-transplant PHT and 30-day mortality or a long-term survival.

Conclusions. In our cohort, PHT dropped very quickly after $\mathrm{HTX}$, and was not associated with acute right heart failure following the surgery. Reversible PTH does not have a negative impact on short- or long-term survival after HTX.

Key words: acute rejections, heart transplantation, infections, pulmonary hypertension, survival

Received: November 27, 2011; Accepted: February 23, 2012; Available online: May 10, 2012

http://dx.doi.org/10.5507/bp.2012.026

${ }^{a}$ Center of Cardiovascular and Transplant Surgery, Pekarska 53, Brno, Czech Republic

'International Clinical Research Center, Pekarska 53, Brno

'Department of Cardio-Angiology, St. Anne's University Hospital in Brno, Pekarska 53, Brno

Corresponding author: Helena Bedanova, e-mail: hbedanova@seznam.cz

\section{INTRODUCTION}

The prognostic impact of pulmonary hypertension before and after heart transplantation is debated. In the 1971s Griepp at al. ${ }^{1}$ first reported the relationship between elevated preoperative pulmonary vascular resistance and risk of death from acute right ventricular (RV) failure after heart transplantation. Also other studies confirmed this association ${ }^{2-4}$. Subsequent analyses of larger number of patients confirmed PVR as an incremental risk factor for early death after transplantation. Indeed, preoperative pulmonary hypertension and increased PVR have not only been associated with post-transplant morbidity from acute RV failure and higher perioperative mortality, but they have also has been associated with other causes of postoperative morbidity, including post-transplant infections and arrhythmias. Irreversible pulmonary hypertension is one of the main factors that contraindicate heart transplantation.

On the other hand, the number of HTx candidates, refused due to irreversible PTH is not high ${ }^{6,7}$.

This issue remains a cause of academic controversy and uncertainty resulting is a number of diagnostic and treatment algorithms suggested in various guidelines (use of prostaglandin E1, prostacyclin, inhaled nitric oxide, sildenafil and assist devices or their combinations) ( ref. $^{8}$ ). Also values of PVR and transpulmonary pressure gradient (TPG), which are still considered compatible for transplantation, differ from country to country and even from institution to institution.

The aim of our retrospective analysis was to assess effect of pulmonary hypertension on the early course after HTx and to determine whether the presence of reversible PTH may impact the morbidity of these patients and their long-term survival.

\section{MATERIALS AND METHODS}

\section{Patients}

We performed a retrospective analysis of 149 consecutive heart transplant recipients operated from January 2000 to December 2007. The mean duration of the followup was $5.6+/-3.8$ years. We excluded children $<18$ years of age $(n=7)$, patients with re-transplantation $(n=3)$ and recipients of multiple organs (heart-liver, heart-kidney and heart-liver-kidney) transplantation $(n=5)$. 
In patients with PVR > 3.5WU (Wood units) the vasodilatator alprostadil was used in declining order of frequency to achieve the required value mandatory for HTx in our center (PVR $\leq 3.5 \mathrm{WU})$. Patients with irreversible PTH were not accepted for heart transplantation. All cardiac transplantations were performed using bi-caval technique.

The immunosuppressive protocol consisted of dual- or triple-drug immunosuppression, in maintenance therapy with cyklosporine A (Ciclosporinum - Sandimmunn Neoral, Novartis, Nyon, Switzerland) or tacrolimus (Tacrolimusum - Prograf, Astellas Pharma, INC, Deerfield IL, US ), mycophenolate mofetil (Mofetilis mycophenolas - Cellcept, Roche, Basel, Switzerland) and corticosteroids (in $10 \%$ of patients). All patients received initial induction therapy of daclizumab (Daclizumab - Zenapax, Roche, Basel, Switzerland). Daclizumab was routinely administrated in the direct postoperative phase, as well as statins in the maintenance therapy ${ }^{9}$.

Further, we observed incidence of acute cellular rejections (AR), bacterial, viral and fungal infections, duration of hospitalization, 30-day mortality and a long-term survival.

The study was approved by local Institutional Ethics Committee (Protocol No. 118/2008).

Because of the retrospective nature of the study no consent form was obtained.

\section{Right heart cathetrization}

Right heart cathetrization was performed using a Swan-Ganz pulmonary artery thermodilution catheter annually on the waiting list at 3-month intervals, before HTx at the operating theatre and then in the early posttransplant period. The following pressures were recorded (in $\mathrm{mm} \mathrm{Hg}$ ): mean pulmonary artery pressure (MAP), mean pulmonary capillary wedge pressure (PCW), by thermodilution was measured cardiac output $(\mathrm{CO})$ and cardiac index (CI) was calculated by dividing $\mathrm{CO}$ by body surface area. The transpulmonary gradient was obtained by subtracting PCW from MAP and PVR in Wood units by dividing TPG with CO. If there was unacceptable PVR, a vasodilatation test with alprostadil (Alprostadilum Alprostan, Zentiva, Czech Rep.) was performed.

\section{Echocardiography}

Echocardiographic data were obtained for all patients before HTx and during follow-up examinations after the procedure. During the first week post HTx, echocardiograms were performed daily, later once per week. In all exams, these parameters were recorded and analyzed by an experienced clinician: ejection fraction of left ventricle (LVEF) and severity of tricuspid valve regurgitation as a marker of right ventricle failure. All measurements were assessed from transthoracic echocardiogram in the apical 4-chamber view. Severity of TR was assessed using a semiquantitative 4 grade scale.

\section{Statistical Analysis}

Results for continuous variables are presented as means \pm standard deviation and for categoric variables as frequency (percent). Three-group comparisons for continuous variables were made using ANOVA. The Fisher exact probability test and Student's t-test were used for comparison of continuous variables. Survival estimates were generated by the Kaplan-Meier method. The longrange test was utilized to compare survival across groups, and $P \leq 0.05$ was considered statistically significant.

\section{RESULTS}

The baseline characteristics of all patients are presented in Table 1. There were no differences among the three groups in age, gender, BMI, distribution of diagnosis

Table 1. Recipient Characteristics in Group A, Group B and Group C.

\begin{tabular}{|c|c|c|c|}
\hline & Group A & Group B & Group C \\
\hline $\mathrm{N}$ & 84 & 50 & 15 \\
\hline Age $($ mean $\pm \mathrm{SD})$ & $52 \pm 6.9$ & $51 \pm 7.9$ & $54 \pm 5.3$ \\
\hline Male (\%) & 88 & 78 & 80 \\
\hline \multicolumn{4}{|l|}{ Pre-operative Dg } \\
\hline Ischemic CM (\%) & 40 & 56 & 67 \\
\hline Dilated CM (\%) & 52 & 40 & 27 \\
\hline Other $(\%)$ & 8 & 4 & 6 \\
\hline Urgent waiting list (\%) & 54 & 62 & 67 \\
\hline \multirow[t]{2}{*}{ Waiting time (days) } & U 35 & U 52 & $\mathrm{U} 40$ \\
\hline & $\mathrm{N} 180^{\mathrm{a}}$ & N 112 & N 103 \\
\hline Body mass index & $26.3 \pm 2.9$ & $24.6 \pm 2.7$ & $26.1 \pm 2.9$ \\
\hline
\end{tabular}

$\mathrm{CM}$ - cardiomyopathy; $\mathrm{U}$ - urgent; $\mathrm{N}$ - non-urgent list

${ }^{a} P \leq 0.05$ - statistically significant 
Table 2. Donor Characteristics in Group A, Group B and Group C.

\begin{tabular}{lccc}
\hline & Group A & Group B & Group C \\
\hline $\mathrm{N}$ & 84 & 50 & 15 \\
Age (mean \pm SD) & $34 \pm 10.3$ & $36 \pm 11.8$ & $38 \pm 10.8$ \\
Male (\%) & 89 & 76 & 80 \\
Cause of death & & & 53 \\
Craniotrauma (\%) & 73 & 56 & 67 \\
Other (\%) & 27 & 44 & 173 \\
CIT (min) & 162 & 161 & 61 \\
LV EF (\%) & 60 & 59 & $24.9 \pm 3.0$ \\
Body mass index & $25.0 \pm 2.0$ & $24.0 \pm 1.9$ & 24.9 \\
\hline
\end{tabular}

CIT - cold ischemia time; LV EF - left ventricle ejection fraction;

Table 3. Hemodynamics before and early after Heart Transplantation in Group A, Group B and Group C.

\begin{tabular}{lccc}
\hline & Group A & Group B & Group C \\
\hline $\mathrm{N}$ & 84 & 50 & 15 \\
\hline & Preoperative & & \\
\hline Cardiac output $(\mathrm{mL} / \mathrm{kg})$ & $3.72 \pm 0.7$ & $3.20 \pm 0.5$ & $2.91 \pm 0.4$ \\
Cardiac index $(\mathrm{mL} / \mathrm{kg} / \mathrm{min})$ & $1.83 \pm 0.4$ & $1.75 \pm 0.4$ & $1.50 \pm 0.2$ \\
Transpulmonary gradient $(\mathrm{mmHg})$ & $7.4 \pm 1.9$ & $11.8 \pm 2.9$ & $18.9 \pm 4.0$ \\
Pulmonary pascular resistence $(\mathrm{WU})$ & $2.1 \pm 0.5$ & $3.5^{\mathrm{a}} \pm 0.4$ & $6.9^{\mathrm{a}} \pm 1.4$ \\
\hline & Day 1 after heart transplantation & \\
\hline Cardiac output $(\mathrm{mL} / \mathrm{kg})$ & $5.26 \pm 1.1$ & $5.09 \pm 1.4$ & $5.02 \pm 1.7$ \\
Cardiac index (mL/kg/min) & $2.69 \pm 0.6$ & $2.67 \pm 0.7$ & $2.60 \pm 0.8$ \\
Transpulmonary gradient $(\mathrm{mmHg})$ & $10.2 \pm 2.0$ & $10.4 \pm 1.9$ & $11.2 \pm 1.6$ \\
Pulmonary pascular resistence $(\mathrm{WU})$ & $2.1 \pm 0.6$ & $2.3^{\mathrm{a}} \pm 0.6$ & $2.5^{\mathrm{a}} \pm 0.7$ \\
\hline
\end{tabular}

${ }^{a} P \leq 0.05$ - statistically significant $P=1.82 \times 10^{-16}$ in Group B, $P=5.89 \times 10^{-8}$ in Group C

and ratio of urgent vs.non-urgent waiting list recipients. Only the waiting time on the non-urgent waiting list was significantly longer in group A.

The characteristics of donors are displayed in Table 2. There were no significant differences among the three groups in average age, gender, BMI, LVEF, cold ischemia time or cause of death.

According to their hemodynamic measurements the patients were divided into 3 groups: Group A ( $n=84)$ without pulmonary hypertension $(\mathrm{PTH})$ with PVR $<3 \mathrm{WU}$, group B $(n=50)$ with mild to moderate PTH with PVR 3-5 WU and group $\mathrm{C}(\mathrm{n}=15)$ with severe PTH with PVR $>5$ WU.

The hemodynamic data of all patients and comparisons among the groups are presented in Table 3. Recipients in groups 2 and 3 had higher mean PVR and TPG and as shown in Table 3 PVR reached normal range $(2.5 \pm 0.6 \mathrm{WU})$ on Day 1 in all groups. Significant decreases in mean PVR were observed in groups B and C. Vasodilator treatment (nitric oxide or alprostadil or their combination) was used in $32 \%$ of patients in
Group A, 46\% in Group B and in over $80 \%$ of patients from group $\mathrm{C}$.

There were no significant differences in the severity of post-transplant TR among the 3 groups early after HTx (severe TR was observed in 46\%, 54\% and 33\%, respectively). Interestingly, a statistically significant portion of patients from group B presented with moderate or worse TR one month after HTx (4\%, 11\% and 2\%, respectively).

No significant difference was found during the followup period between groups in terms of incidence of AR (Grade $\geq 2$ Banff classification) (23\%, 23\%, 33\%, respectively), overall infections (28\%,32\%, 33\%, respectively) as shown in Fig. 1 and 2. Average duration of hospitalization was practically identical for the 3 groups (30, 30, 28 days, respectively).

There was no correlation between pre-transplant PTH and 30-day mortality or a long-term survival. Fig. 2 presents survival curves for the three groups. The 30-day mortality was 7\% in Group A, 4\% in Group B and 0\% in group C. One-year survival calculated by the KaplanMeier analysis was $87 \%, 84 \%$ and $93 \%$ in groups A,B and 
Table 4. Echocardiografic Parameters-Tricuspidal Regurgitation and Left Ventricle Ejection Fraction in Day 1 and 1 Month after Heart Transplantation in Group A, Group B and Group C.

\begin{tabular}{lccc}
\hline & Group A & Group B & Group C \\
\hline $\mathrm{N}$ & 84 & 50 & 15 \\
\hline & Day 1 after heart transplantation & & 33 \\
\hline TR > Grade 2 (\%) & 46 & 54 & 54 \\
LV EF (\%) & 52 & 52 & $80^{\mathrm{a}}$ \\
Alprostadil and/or NO therapy (\%) & 32 & 46 & $2^{\mathrm{a}}$ \\
\hline & 1 month after heart transplantation & 64 \\
\hline TR $>$ Grade 2 (\%) & $4^{\text {a }}$ & $11^{\mathrm{a}}$ & 62 \\
\hline
\end{tabular}

TR - tricuspid regurgitation; LV EF - left ventricle ejection fraction

${ }^{a} P \leq 0.05$ - statistically significant in all groups

C, respectively and the 5-year survival was $81 \%, 76 \%$ and $93 \%$, respectively.

\section{DISCUSSION}

The main findings in the present study are the following. (I) pre-transplant PTH (including severe) when reversible, does not influence short-or long-term survival after HTx; (II) hemodynamic variables improve to nearnormal values within the first several days in most HTx recipients and (III) pre-transplant $\mathrm{PH}$ is not associated with increased risk of acute graft rejections or infections.

Left heart disease is the most common cause of pulmonary hypertension. Increased left-sided filling pressure leads to passive postcapillary venous hypertension. In some patients, pulmonary vasoconstriction and vascular remodeling may lead to a further increase in pulmonary pressure. When the precapillary hypertension component is associated with left heart failure, the elevation of pulmonary pressure is out of proportion to left atrial pressure: a transpulmonary gradient greater than $12 \mathrm{mmHg}$ and pulmonary vascular resistance greater than three WU. Precapillary pulmonary hypertension is common in severe systolic heart failure. Before cardiac transplantation, increased pulmonary vascular resistance greater than 3.5 WU is reported in 19 to $35 \%$ of patients ${ }^{10}$. Fixed (ireversible) PTH is one of the main contraindications for HTx because of the risk of developing fatal right heart failure after transplantation. In order to prevent this, a number of medications and/or techniques (prostaglandin E1, prostacyclin, inhaled nitric oxide and ventricular assistance devices) have been proposed and are used to decrease pulmonary pressures. Most of these treatment strategies have been aimed at the management of patients with primary pulmonary hypertension but they have turned out to be very useful in the preoperative conditioning of patients with secondary pulmonary hypertension stemming from chronic heart failure ${ }^{11-13}$. New approaches based on treatment of heart transplant candidates with pulmonary hypertension have increased the number of patients suitable for placement on the waiting list and additionally it has shown beneficial effect on survival after HTx. Recently, sildenafil, a fosfodiesterase-5-inhibitor and traditional drug for erectile dysfunction treatment, has been successfully introduced into the algorithms for testing and treatment of pre-transplant pulmonary hypertension ${ }^{14-17}$.

Elevated PVR in heart transplant candidates can also be reduced using a left ventricular assist device. Several studies have recently reported the successful results of this new treatment strategy and therefore LVAD is proposed as the treatment of choice for candidates with pulmonary hypertension ${ }^{18-20}$. Interestingly, LVAD support has been successful in those transplant candidates who retained elevated pulmonary pressures after drug testing and therefore were initially excluded from HTx waiting list. These novel findings have motivated Andrea G to raise a controversial question "Is fixed severe pulmonary hypertension still a contraindication for heart transplant in the modern era of mechanical circulatory support?"( ref. $\left.^{21}\right)$. It is worth nothing that normal preoperative PVR does not rule out increased PVR and acute RV failure after HTx. Organ preservation and cardiopulmonary bypass also have deleterious effects on ventricular function ${ }^{22-24}$. The previous common practice of using oversized donors for recipients with $\mathrm{PH}$ has been found unnecessary ${ }^{25}$.

Our study has several limitations. The retrospective design has disadvantages compared with prospective study. When the data were collected, neither sildenafil nor LVAD were eligible for use in HTx candidates and therefore were not included in the testing and treatment. Due to the retrospective nature of the protocol, echocardiographic assessment of right heart failure comprises semiquantitative evaluation of tricuspid regurgitation and right ventricular function. Our study lack hemodynamic data from right heart catheterization during the followup period.

Gude et al. has recently published results showing that reversible $\mathrm{PH}$ assessed by right heart catheterization prior to HTx had no negative impact on post-HTx outcomes $^{7}$. These findings are in accordance with our results. Interestingly, they have shown association between the 

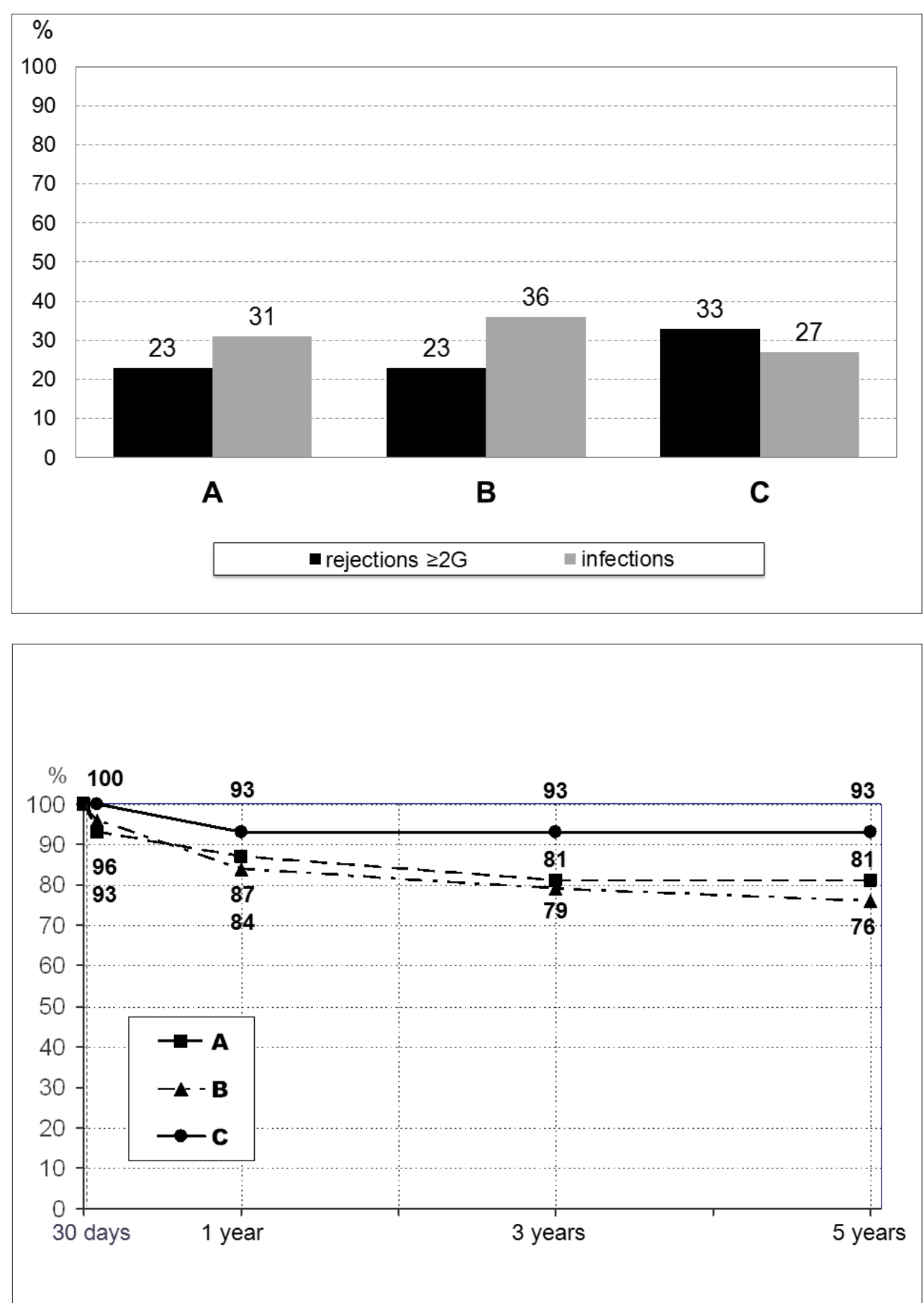

Fig. 1. Days of hospitalization for Groups A-C.

Fig. 2. Kaplan-Meier curves of survival for Groups A-C. presence of PTH 1 year after HTx and reduced survival. Therefore further studies with long follow-up are required to explain these findings and propose rational treatment strategies to improve survival rates.

\section{CONCLUSIONS}

In our cohort, PHT dropped very quickly after HTx, and was not associated with acute right heart failure following the surgery. Reversible PTH does not have a negative impact on short- or long-term survival after HTx.

\section{ACKNOWLEDGEMENTS}

Helena Bedanova MD, PhD. designed the research protocol, collected data and prepared the final manuscript. Marek Orban MD, Lenka Spinarova MD, Petr Hude MD and Jan Krejci MD were responsible for data collection, manuscript preparation and data analysis, Dusan Vrsansky MD, FESc. for data analysis, Jiri Ondrasek MD and Petr Nemec MD were involved in data collection process.

Marek Orban and Helena Bedanova were supported by a Grant IGA MZd CR NS 10627-3 and by European Regional Development Fund - Project FNUSA-ICRC No. CZ.1.05/1.1.00/02.0123. 


\section{REFERENCES}

1. Griepp R, Stinson E, Dong E Jr, Clark DA, Shumway NE. Determinants of operative risk in human heart transplantation. Am J Surg 1971;122:192-7.

2. Kirklin JK, Naftel DC, Kirklin JW, Blackstone EH, White-Williams C Bourge RC. Pulmonary vascular resistance and risk of heart transplantation. J Heart Lung Transplant 1988;7:331-6.

3. Erickson K, Constanzo-Nordin MR, O'Sullivan EJ, Johnson MR, Zucker MJ, Pifarré R, Lawless CE, Robinson JA, Scanlon PJ. Influence of preoperative transpulmonary gradient on late mortality after orthotopic heart transplantation. J Heart Transplant 1990;12:549-62.

4. Espinoza C, Manito N, Roca J, Castells E, Mauri J, Ribas M, Claret G. Reversibility of pulmonary hypertension in patients evaluated for orthotopic heart transplantation: importace in the postoperative morbidity and mortality. Transplant Proc 1999;31:2503-4.

5. Bourge RC, Naftel DC, Constanzo-Nordin MR, Kirklin JK, Young JB, Kubo SH, Olivari MT, Kasper EK. Pretransplantation risk factors for the death after transplantation: a multi-institutional study: the Transplant Cardiologist Research Database group. J Heart Transplant. 1993;12:549-62.

6. Lindelow B, Andersson B, Waagstein F, Bergh CH. Prognosis of alternative therapies in patients with heart failure not accepted for heart transplantation. J Heart Lung Transplant 1995;14:1204-11.

7. Gude E, Simonsen S, Geiran OR, Fiane AE, Gullestad L, Arora S, Relbo A, Andreassen AK. Pulmonary hypertension in heart transplantation: Discrepant prognostic impact of pre-operative compared with 1-year post-operative right heart hemodynamics. J Heart Lung Transplant 2010;29:216-23.

8. Stobierska-Dzierzek B, Awad H, Michler RE. The evolving management of acute right-sided heart failure cardiac transplant recipients. J Am Coll Cardiol 2001;38(4):923-31.

9. Petrikovits E, Bedanova H, Necas J, Studenik P, Cerny J. Daclizumab in the induction phase of immunosuppression in heart transplant recipients. Ann Tranpslant 2005;10(3):5-10.

10. Nallet O, Milleron O, Monsel F, Safar B, Ghrissi I, Sergent J. Pulmonary hypertension and heart failure: the role of pulmonary vasculature. Ann Cardiol Angiol 2009;58(5):304-9.

11. Maruszewski M, Zakliczynski M, Prybylski R, Kucewicz-Czech E, Zembala M. Use of sildenafil in heart transplant recipients with pulmonary hypertension may prevent right heart failure. Transplant Proc 2007;39(9):2850-2.

12. Boffini $M$, Sansone $F$, Ceresa F, Ribezzo M, Patanè $F$, Comoglio $C$, Rinaldi $M$. Role of oral sildenafil in the treatment of right ventricular dysfunction after heart transplantation. Tranplsant Proc 2009;41(4):1353-6.

13. De Santo LS, Mastroianni C, Romano G, Amarelli C, Marra C, Maiello C, Galdieri N, Della Corte A, Cotrufo M, Caianiello G. Role of sildenafil in acute posttransplant right ventricular dysfunction: successful experience in 13 consecutive patients. Transplant Proc 2008;40(6):2015-8.

14. Jabbour A, Keogh A, Hayward C, Macdonald P. Chronic sildenafil lowers transpulmonary gradient and improves cardiac output allowing successful heart transplantation. Eur J Heart Fail 2007;9:674-7.

15. Mogollon MV, Lage E, Cabezon S, Hinojosa R, Ballesteros S, Aranda A, Sobrino JM, Ordóñez A. Combination therapy with sildenafil and bosentan revers severe pulmonary hypertension and allows heart transplantation: case report. Transplant Proc 2006;38(8):2522-3.

16. Gomez-Moreno S, Lage E, Hernandez A, Campos A, Cabezón S, Ordóñez A, Hinojosa R. Use of oral sildenafil in patiens with irreversible pulmonary hypertension not eligible for heart transplantation. Transplant Proc 2005;37(3):1550-1.

17. Zakliczynski M, Maruszewski M, Pyka L, Trybunia D, Nadziakiewicz $P$, Przybylski R, Zembala M. Effectiveness and safety of treatment with sildenafil for secondary pulmonary hypertension in heart transplant candidates. Transplant Proc 2007;39(9):2856-8.

18. Liden H, Haraldsson A, Ricksten SE, Kjellman U, Wiklund L. Does pretransplant left ventricular assist device therapy improve results after heart transplantation in patiens with elevated pulmonary vasculary resistance? Eur J Cardiothorac Surg 2009;35(6):1029-34.

19. Petrofski JA, Hoopes CW, Bashore TM, Russell SD, Milano CA. Mechanical ventricular support lowers pulmonary vascular resistance in a patient with congenital heart disease. Ann Thorac Surg 2003;75(3):1005-7.

20. Kamdar F, Boyle A, Liao K, Colvin-adams M, Joyce L, John R. Effects of centrifugal, axial, and pulsatile left ventricle assist support on end-organ function in heart failure patients. J Heart Lung Transplant 2009;28:352-9.

21. Andrea G, Giuseppe B, Tiziano C, Maria F, Ettore V. Is fixed severe pulmonary hypertension still a contraindication to heart transplant in the modern era of mechanical circulatory support? A review. J Cadiovasc Med 2008;9(10):1059-62.

22. Loganathan S, Radovits T, Hischberg K, Korkmaz S, Koch A, Karck M, Szabó G. Effects of Custodiol-N, a novel organ preservation solution, on ischemia/reperfusion injury. J Thorac Cardiovasc Surg 2010;139(4):1048-56.

23. Koch A, Radovits T, Loganathan S, Sack FU, Karck M, Szabó GB. Myocardial protection with the use of L-arginine and N-alpha-acetylhistidine. Transplant Proc 2009;41(6):2592-4.

24. Dedeoglu BD, Aytac E, Suzer O, Balci H, Uzun H, Seymen P, Seymen HO. Donor heart preservation with iloprost supplemented St. Thomas Hospital cardioplegic solution in isolated rat hearts. Prostaglandins Leukot Essent Fatty Acids 2008;78(6):415-21.

25. Patel ND, Weiss ES, Nwakanma LU, Russell SD, Baumgartner WA, Shah AS, Conte JV. Impact of donor-to-recipient weight ratio on survival after heart transplantation: analysis of the United Network for Organ Sharing Database. Circulation 2008;118:S83-8. 